\title{
COVID-19 Control in Italy: Personal Experience from March 25-April 8, 2020
}

\author{
Fan $\operatorname{Lyu}^{1, *}$
}

To combat the rapidly escalating COVID-19 epidemic in Italy, China's third expert team against the COVID-19 pandemic in Italy departed on March 25, 2020. I joined the expert team on March 25-April 8, 2020. As the chairman of Italian Red Cross, Francesco Rocca, said he appreciated the Chinese experts who, after their arduous work on the front lines of China for over a month, chose to move ahead by flying to Italy to offer help (1). Medical experts of Italian National Institute of infectious diseases said that Chinese experts have gained a great deal of experience that Italy urgently needs, and that due to the considerable success China has had in fighting the epidemic, they wanted to work with Chinese experts on an international level in Italy (2).

However, there have been some concerns on whether China's experience in fighting COVID-19 could also be practical for European countries. In fact, making the best practices and lessons learned in China to be applicable in other regions to solve joint public health issues has been a major challenge for me. The goal of this paper is to introduce my personal experiences working in Italy, which is organized into the following several points: identifying problems through rapid assessment, forming recommendations based on evidence, and communicating for action. In addition, effective preparation is essential to ensure effective and efficient work of international aid.

\section{Key Questions to be Answered}

Italy is a developed country with a high proportion of aging people. Before departure, I had two conceptions about the epidemic situation in Italy: one was the high case-fatality rate of COVID-19 due to its high elderly population structure; the other was the unwillingness to obey preventive measures such as wearing face mask, staying at home, or maintaining social distancing while Italian people pursued democratic values and freedom and making a consensus that only sick people should follow these measures. Public perception and opinions might be major barriers to COVID-19 control in Italy. To provide more effective measures and strategies according to the local situation of the COVID-19 epidemic, the following questions should be answered: what is the actual picture of the COVID-19 epidemic in Italy and what recommended approach is realistic for COVID-19 control in Italy? Detailed information was clearly needed.

\section{Results of Rapid Assessment}

Shortly after arriving in Italy on March 26, a rapid assessment was conducted through literature review, field observation, and communication with local medical staff and residents to obtain more information on their local epidemic status as well as the existing prevention and control strategies. It was observed that most people could wear masks in public and that the government had already taken some strict measures aiming for COVID-19 containment including punishment with detention, fines, or imprisonment to prevent people from gathering or moving unnecessarily, and local medical institutions were found to be capable of providing proper professional treatment for inpatients. In addition, two urgent issues were concluded through the assessment.

First, the risk of family transmission was high because many mild patients were treated at home. In Tuscany, there were 3,786 ongoing cases of confirmed COVID-19 on March 26 including 275 cases in intensive-care units (ICUs), 1,111 cases in hospitals, and 2,400 (about $58.5 \%$ of total cases) cases receiving home care. According to national data which was officially released on March 27, 36,653 cases (42\% of the total) were found to be infected during home isolation. In light of this, we advised the local government to strengthen the standard management of home care for mild patients and consider centralized treatment for such patients, and the proposal was also strongly endorsed by Italian experts. According to Reuters on March 30, Andrea Crisanti, a microbiology professor at the University of Padua, said that measures in Italy to prevent the spread of COVID-19 appeared to be ineffective and should be changed. Crisanti said that instead of telling people with mild symptoms to self-isolate at home with the rest of their family, the 
authorities should set up centers to separate them from their families as was done in China (3).

Second, viral nucleic acid testing was insufficient locally. According to medical staff and health authorities we interviewed shortly after arriving in Tuscany, nucleic acid testing had been mainly carried out for some hospitalized patients and some patients with high fevers who sought medical treatment in Tuscany. The percentage of positive tests in Italy was as high as about $15 \%$, and the proportion of severe cases accounted for $28 \%$ of total confirmed cases. It seemed likely that a number of infections might have been neglected and have become the potential sources of infections. Delays in testing result in not only late diagnoses but also a higher case-fatality rate. Based on this, scaling-up testing was strongly recommended.

Following the recommendations, the local authorities in Tuscany have begun to rent hotels for centralized treatment of some mild patients since March 31, and the number of tests gradually increased since late March.

\section{Key Lessons from Working in Italy}

I have three key points for effective work in aiding the fight against COVID-19 based on my personal experiences in Italy.

Effective preparation: The important task of assisting Italy involved sharing Chinese experience. Members of China's expert teams should be familiar with China's experiences of COVID-19 prevention and control including integrated prevention and control systems, specific technical guidelines and programs, and cutting-edge research findings including knowledge about the pathogens, transmission dynamics, and strategic concerns of the disease (4-6). In addition, it is also essential to consult experts of former teams about their experiences in aiding Italy. Finally, a supportive network of talent needs to be established and could be composed of experts from diverse fields including disinfection, laboratory testing, and the global health center experts, etc.

Rapid risk assessment to understand local contexts: We interviewed local medical staff, prevention and control personnel, overseas Chinese people, etc., in order to gain a comprehensive understanding of the current status of local epidemics and control and prevention work. It is important to accurately identify the strong links and weak links of the prevention and control strategy through an integrated analysis of the information gathered from this rapid assessment. The results from analysis should provide strong evidence to make recommendations for a local strategy for COVID-19 control and prevention. This is key for making practical recommendations based on China's experiences and the local conditions in Italy.

Communicating for action: Three recommendations were formed based on the results of our rapid risk assessment, two of which were accepted by local authorities (centralizing treatment of mild patients and scaling-up of testing). The third recommendation was to strengthen epidemiological investigations as epidemiological investigations of confirmed cases were insufficient. We further recommended that the local team strengthen epidemiological investigations in order to find close contacts and to promptly test and quarantine these contacts. However, after discussion with local professionals, the recommendation could not be adopted due to limited human resources. Therefore, interviewing local people with local knowledge is one of the determinants to making recommendations more appropriate and feasible in local contexts.

Acknowledgements: I would like to thank all members of the China's third expert team against the COVID-19 pandemic in Italy. It is appreciated that Professor George F. Gao gave me advice and motivate me to share these experiences. Thanks Professor Feng Tan, Dr. Fangfang Chen, Dr. Zhilong Dong, and all experts and volunteers who provided help.

doi: $10.46234 / \mathrm{ccdcw} 2020.096$

\# Corresponding author: Fan Lyu, fanlv@chinaaids.cn.

${ }_{1}$ National Center for AIDS/STD Control and Prevention, China
Center for Disease Control and Prevention, Beijing, China. Submitted: May 10, 2020; Accepted: May 20, 2020

\section{REFERENCES}

1. Xinhua. China's expert team, medical supplies fly into Rome. http://www. xinhuanet.com/english/2020-03/13/c_138872569.htm. [2020-05-14].

2. The People's Daily. Italian Red Cross: Thanks for China's expert team. https://baijiahao.baidu.com/s?id=1661395793036747887\&wfrspider\&f orpc. [2020-05-07]. (In Chinese)

3. Bernabei S. Italy may be on wrong path in fighting coronavirus contagion: scientist. Political News, Analysis and Opinion. https:// infantry-center.com/2020/03/30/italy-may-be-on/. [2020-03-30].

4. Li Q, Guan XH, Wu P, Wang XY, Zhou L, Tong YQ, et al. Early transmission dynamics in Wuhan, China, of novel coronavirus-infected pneumonia. N Engl J Med 2020;382(13):1199 - 207. http://dx.doi.org/ 10.1056/NEJMoa2001316.

5. Zhu N, Zhang DY, Wang WL, Li XW, Yang B, Song JD, et al. A novel coronavirus from patients with pneumonia in China, 2019. N Engl J Med 2020;382(8):727 - 33. http://dx.doi.org/10.1056/NEJMoa2001017.

6. Wang C, Horby PW, Hayden FG, Gao GF. A novel coronavirus outbreak of global health concern. Lancet 2020;395(10223):470 - 3 . http://dx.doi.org/10.1016/S0140-6736(20)30185-9. 